\title{
Left Atrial Appendage Closure
}

\section{Where Do We Stand Now?}

\author{
J. Mauricio Sánchez, MD ${ }^{1 *}$ and David R. Holmes, Jr., MD² \\ ${ }^{1}$ Department of Cardiac Electrophysiology, The Heart Health Center, Mercy Clinic, St. Louis, Missouri, USA \\ ${ }^{2}$ Department of Cardiology, Mayo Clinic, Rochester, Minnesota, USA
}

\begin{abstract}
Atrial fibrillation is the most common arrhythmia with significant morbidity and mortality. The most feared complication of atrial fibrillation remains stroke. While anticoagulation remains the cornerstone of stroke prevention in patients with atrial fibrillation, patients continue to be under treated due to misinformation, intolerance, as well as relative and absolute contraindications. The left atrial appendage has been implicated in thrombus formation in patients with atrial fibrillation. Left atrial appendage closure has been devised as an alternative strategy for decreasing stroke risk in patients with atrial fibrillation. Percutaneous left atrial appendage closure is currently being developed as a possible alternative to anticoagulation in patients at high risk for stroke especially among patients with relative or absolute contraindications to long-term anticoagulation. The PROTECT AF trials provides the first randomized, controlled trial data demonstrating proof of concept of left atrial appendage closure with the WATCHMAN device. Further data are explored in this review. Limited data are available with other devices. However, several devices are promising entries into the realm of left atrial appendage closure offering options to an under treated patient population.

Copyright @ 2016 Science International Corp.
\end{abstract}

\section{Key Words}

Atrial Fibrillation - Left atrial appendage - Left atrial appendage closure - Stroke - Thromboembolism • Bleeding

ax +1 2037853346

E-Mail: jshd@scienceinternational.org

http://structuralheartdisease.org/ (c) 2016 Journal of Structural Heart Disease Published by Science International Corp. ISSN 2326-4004

Accessible online at:

http://structuralheartdisease.org/

\section{Introduction}

Atrial fibrillation (AF) is the most common arrhythmia, with an overall incidence of $0.4 \%$ to $1 \%$ in the general population [1-3]. The prevalence of AF increases with age. Given an aging population, the number of patients with AF is likely to increase in the near future. The estimated prevalence in 2010 ranged between 2.1 million and 6.1 million. By 2050, this is projected to increase to between 5.6 and 12 million patients [4], which will present significant challenges for health care delivery. AF results in chaotic atrial contraction and subsequent loss atrial transport function, which impairs left ventricular filling and promotes stasis. The resultant symptoms can range from absent to severe. $\mathrm{AF}$ is associated with significant increase in morbidity including congestive heart failure [5], dementia [6], and significant increase in mortality. The most feared complication of AF is stroke from thromboembolism. Patients with AF are at a five times higher risk of stroke [7]. This risk increases with age [8]. Strokes in $\mathrm{AF}$ patients are often more severe than in non-AF related strokes [9].

Anticoagulation with vitamin $\mathrm{K}$ antagonists has been the cornerstone of stroke prevention in AF patients at high risk for embolic stroke. Vitamin $\mathrm{K}$ antagonists have been shown to decrease incidence of thromboembolic stroke in these patients as well as

*Corresponding Author:

J. Mauricio Sánchez, MD

Department of Cardiac Electrophysiology

The Heart Health Center

West Wing, Suite 170, St. Louis, MO, 63141

Tel.: +1 314991 6969; Fax: +1 314997 6969; E-Mail: Jsanchez@Hearthealthcenter.com 
decreasing the associated mortality from stroke [10]. In clinical practice however, patients who are warfarin eligible are often not treated [11]. In addition, approximately a quarter of patients who initiate therapy will discontinue its use at 1 year [12]. Novel oral anticoagulants (NOAC) have been shown to be non-inferior or superior compared to warfarin but also have discontinuation rates of between $17-25 \%$ at 2 years [1315]. Complications from anticoagulation, including bleeding, intolerance, and falls, present challenges to traditional therapy and NOACs alike.

The left atrial appendage (LAA) is known play a significant role in thrombus formation and stroke in $A F$, with approximately $90 \%$ of thrombi located in the LAA in patients with nonvalvular AF based on echocardiographic and autopsy data [16]. Percutaneous LAA closure has emerged as an alternative strategy for reducing risk of thromboembolic stroke in patients with nonvalvular AF. Understanding the history of LAA closure and the emergence of current percutaneous technologies is imperative to the understanding of the developing field and future indications.

\section{The Left Atrial Appendage}

The LAA is a complex structure that is a remnant of the embryological left atrium. This pouch-like projection has a variety of morphologic appearances and anatomy with variable size, length, width, and number of lobes. In the setting of AF, poor atrial transport function results in stasis within the LAA. This can be documented by low Doppler inflow velocities on transesophageal echocardiography (TEE) and by spontaneous echo contrast, which are both associated with increased risk of stroke [17]. The walls can have a significant amount of trabeculations which may predispose to stroke [18]. Four main morphologies have been characterized based on appearance including: chicken wing, cactus, wind sock, and cauliflower. Non-chicken wing morphologies are significantly more likely to be associated with a thromboembolic event [19] even after controlling for traditional risk factors $\left(\mathrm{CHADS}_{2}\right.$ score.) Other factors such as endothelial dysfunction, inflammation, platelet activation, and hypercoagulable state have also been implicated in having a role the increased risk of thromboembolism [20, 21]. Assessment of stroke risk in AF remains of paramount importance. Utilization of the $\mathrm{CHADS}_{2}$ score previously and now $\mathrm{CHA}_{2} \mathrm{DS}_{2} \mathrm{VASC}$ score [22] is recommended to determine patient risk per year of stroke and subsequent need for possible anticoagulation (Table 1).

Oral anticoagulation utilizes a systemic approach to decrease thrombus formation and subsequent thromboembolism. In contrast, LAA closure provides a local therapy to achieve a similar result. LAA closure is especially appealing in patients intolerant or with contraindications to systemic anticoagulation.

Table 1: $\mathrm{CHADS}_{2}$ and $\mathrm{CHA}_{2} \mathrm{DS}_{2}-\mathrm{VAS}$ for ischemic stroke

\begin{tabular}{|c|c|c|c|c|c|}
\hline \multirow[t]{2}{*}{$\mathrm{CHADS}_{2}$} & \multicolumn{5}{|c|}{$\mathrm{CHA}_{2} \mathrm{DS}_{2}-\mathrm{VAS}_{\mathrm{C}}$} \\
\hline & Risk Factor & Points & & Risk Factor & Points \\
\hline C & Congestive heart failure & 1 & C & Congestive heart failure & 1 \\
\hline $\mathrm{H}$ & Hypertension & 1 & $\mathrm{H}$ & Hypertension & 1 \\
\hline$A$ & Age 75 years & 1 & $\mathrm{~A}_{2}$ & Age 75 years & 2 \\
\hline $\mathrm{D}$ & Diabetes mellitus & 1 & D & Diabetes mellitus & 1 \\
\hline \multirow[t]{4}{*}{$\mathrm{S}_{2}$} & Previous stroke or TIA & 2 & $\mathrm{~S}_{2}$ & Previous stroke or TIA & 2 \\
\hline & & & V & Vascular disease & 1 \\
\hline & & & $A$ & Age 65-74 years & 1 \\
\hline & & & Sc & Sex (female gender) & 1 \\
\hline Maximum score & & 6 & & & 9 \\
\hline
\end{tabular}




\section{Surgical Closure}

Surgical closure of the LAA has been performed for many years with mixed results. The first reported cases of LAA exclusion in the surgical literature was in 1949, in two patients with recurrent arterial emboli [23]. Since that time, surgical ligation has fallen in and out of favor. TEE assessment has shown surgical techniques to have a high occurrence of unsuccessful closure. Success is dependent on the surgical technique utilized with excision providing the best results [24]. Currently, LAA excision is performed usually as an additional procedure with cardiac surgery or as part of a surgical MAZE procedure. Thoracoscopic LAA excision is mainly performed with thoracoscopic surgical pulmonary vein isolation [25], though stand-alone procedures have been reported [26, 27]. There has been a lack of large, randomized, controlled trials with evaluation of long-term stroke risk after surgical LAA closure. Currently, the Left Atrial appendage Occlusion Study (LAAOS III) is being conducted to evaluate LAA occlusion during on-pump cardiac surgical procedures. It is a large-scale randomized controlled trial with an enrollment goal of 4,700 patients with AF. The end-point will be first occurrence of stroke or systemic arterial embolism over a mean follow up of 4 years.

Surgical clip devices have been developed in order to more predictably close the LAA during cardiac surgical procedures. The AtriClip system (AtriCure-USA, West Chester, Ohio, USA) and the Tigerpaw system (Maquet, Rastatt, Germany) are available in the United States [28, 29]. Advantages of use include utilization with live TEE guidance to evaluate position of the clip prior to final closure. While observational studies have demonstrated safety and feasibility of clip based LAA closure, there are no randomized, controlled trial data demonstrating efficacy with regard to stroke prevention. These devices are usually utilized in patients undergoing cardiac surgery, though stand-alone thoracoscopic implantation has been reported with the AtriClip [30]. Further data should help further delineate the effect on clinical outcome of surgical closure with these novel devices.

\section{Transcatheter Closure}

Percutaneous transcatheter approaches have been developed to close the LAA. The inherently less-invasive nature compared to surgical techniques has resulted in significant enthusiasm for transcatheter LAA closure as possible alternative to anticoagulation in patients with nonvalvular AF at high risk for stroke especially among patients with absolute or relative contraindications to long-term anticoagulation. A variety of devices and techniques have been developed with individual development histories and studies which dictate individual efficacy and safety outcomes. Below we discuss, the most frequently studied devices.

\section{PLAATO}

The PLAATO device was the first transcatheter LAA occlusion system developed and implanted in humans [31]. The device was a self-expanding nitinol cage covered with an occlusive expanded polytetrafluoroethylene membrane. It was delivered through a trans-septal access into the left atrium via femoral vein. Initial studies demonstrated that transcatheter closure of the LAA with the PLAATO device was feasible and safe in a nonrandomized study of patients at high risk for thromboembolism who were not able to receive warfarin therapy. When compared to expected event rates based on CHADS $_{2}$ score, the PLAATO device decrease events by $42-65 \%[32,33]$. The PLAATO system was withdrawn from the market in 2006 due to commercial reasons.

\section{Amplatzer Cardiac Plug}

The Amplatzer cardiac plug (St. Jude Medical, Minneapolis, Minnesota, USA) also known as ACP device was developed specifically for LAA closure. The ACP device is a self-expanding nitinol mesh connected to a polyester disk through a central waist (Figure 1). The soft lobe mesh is deformable and deploys distally with anchors that insert into the LAA. This maintains device stability within the LAA. The disk covers the ostium of the LAA sealing it. The development of this device followed the success of the AMPLATZER septal occluder device for patent formen ovale and atrial septal defects. The ACP device is delivered through the femoral vein into the left atrium via transseptal access and requires fluoroscopy and TEE guidance. Patients with the ACP device are maintained on dual 


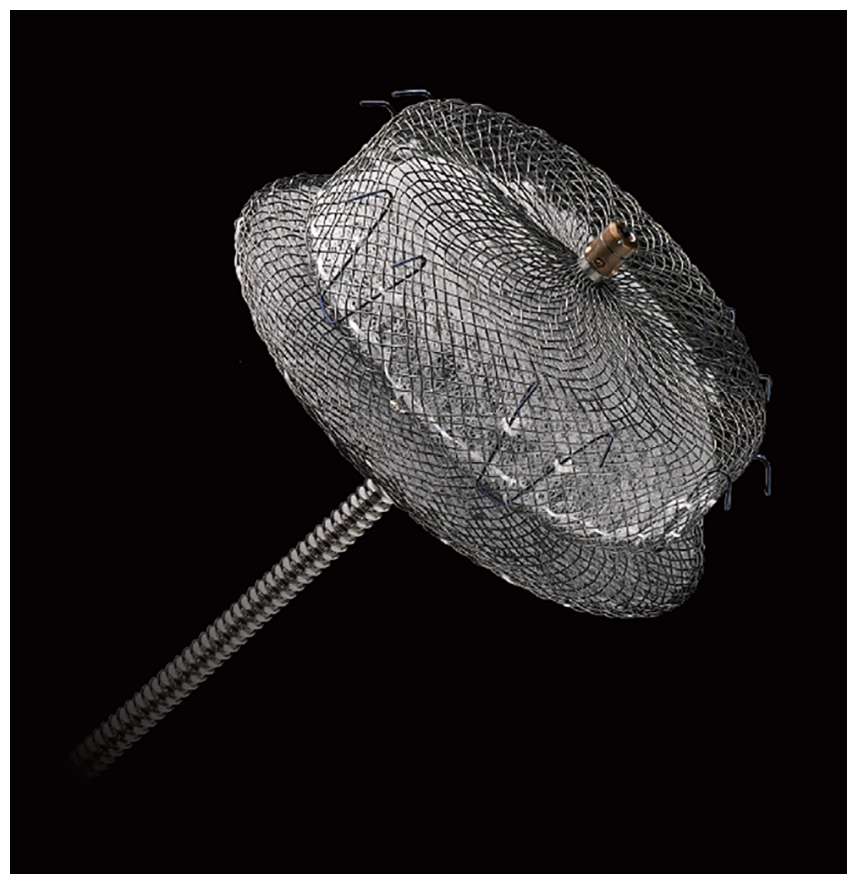

Figure 1. Amplatzer cardiac plug (ACP) device. The ACP device is a self-expanding nitinol mesh connected to a polyester disk through a central waist. The soft lobe mesh is deformable and deploys distally with anchors that insert into the LAA. This maintains device stability within the LAA. The disk covers the ostium of the LAA sealing it (image courtesy of St. Jude Medical, Inc.).

antiplatelet therapy for 1 to 3 months followed by aspirin alone for at least 5 months. Data for this device are limited and consist mainly of small, observational studies in patients not able to take anticoagulation. Initial trials in Europe demonstrated a high rate of procedural success, with $96 \%$ of patients successfully implanted in 137 patients [34]. Serious complications were reported in 10 patients (7\%), including ischemic stroke, device embolization, and serious pericardial effusion. Data from the Asia Pacific experience and Canadian experience have demonstrated a similar high rate of implant success and similar rate of procedural complications [35, 36]. Thrombus formation on the device has been reported [37-39]. The ACP device has CE mark approval but is not approved in the United States at this time. The new ACP 2 device has been implanted with reported improvements in design including an imbedded threaded insert to decrease thrombus formation [40]. In the United States, a large, randomized, controlled trial of the ACP device compared to oral anticoagulation was recently halted in likely anticipation of still pending FDA approval of the WATCHMAN device [41].

\section{WATCHMAN}

The WATCHMAN device (Boston Scientific, Natick, Massachusetts, USA) is the most studied LAA closure device currently in use. It consists of a self-expanding nitinol frame with porous polyethylene terephthalate membrane on the face of the device (Figure 2). The device is delivered through the femoral vein into the left atrium via transseptal access. A 14 French access sheath is carefully maneuvered into the LAA body. The device is loaded into the distal sheath and unsheathed with removal of the access sheath while maintaining distal position of the WATCHMAN device within the LAA. The device is secured in position with fixation barbs present along the sides of the device which engage the endocardium.

This device has CE mark approval. It is the first and only LAA closure device to receive FDA approved in the United States. It was evaluated in a large, randomized, controlled trial in patients with nonvalvular AF who were eligible for warfarin therapy and high risk for thromboembolism. The WATCHMAN Left Atrial Appendage system for Embolic Protection in Patients With Atrial Fibrillation (PROTECT AF) enrolled 707 patients who were candidates for long-term anticoagulation and had nonvalvular AF [42]. The PROTECT AF study was a multicenter non-inferiority trial that randomized patients in a 2:1 fashion to either LAA occlusion with the WATCHMAN device or to warfarin therapy. Patients 18 years old or older with nonvalvular AF were eligible for enrollment with a $\mathrm{CHADS}_{2}$ score greater than or equal to 1 (i.e., at least one of the following: congestive heart failure, hypertension, age greater than 75 years old, diabetes mellitus, previous stroke or transient ischemic attack [43]). Exclusion criteria for the trial included contraindication to aspirin or warfarin, comorbidities other than AF that required chronic warfarin use, LAA thrombus, patent foramen ovale with atrial septal aneurysm and a right-to-left shunt, mobile atheroma, and symptomatic carotid disease. Patients randomized to the device arm were placed on warfarin and aspirin for 45 days postimplantation. Device arm patients then underwent repeat TEE at 45 days of follow up. War- 
A

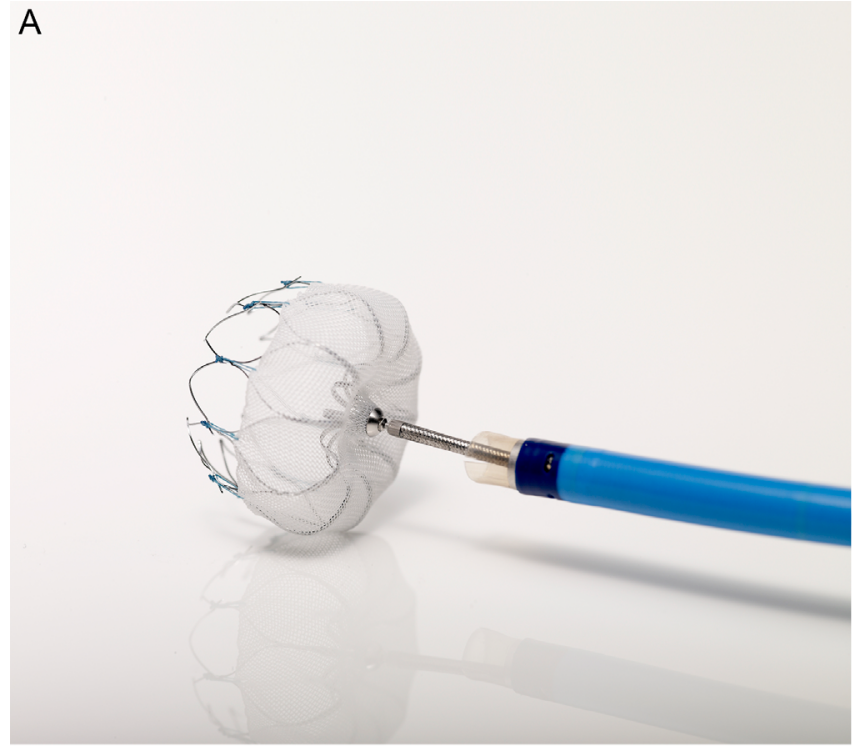

C

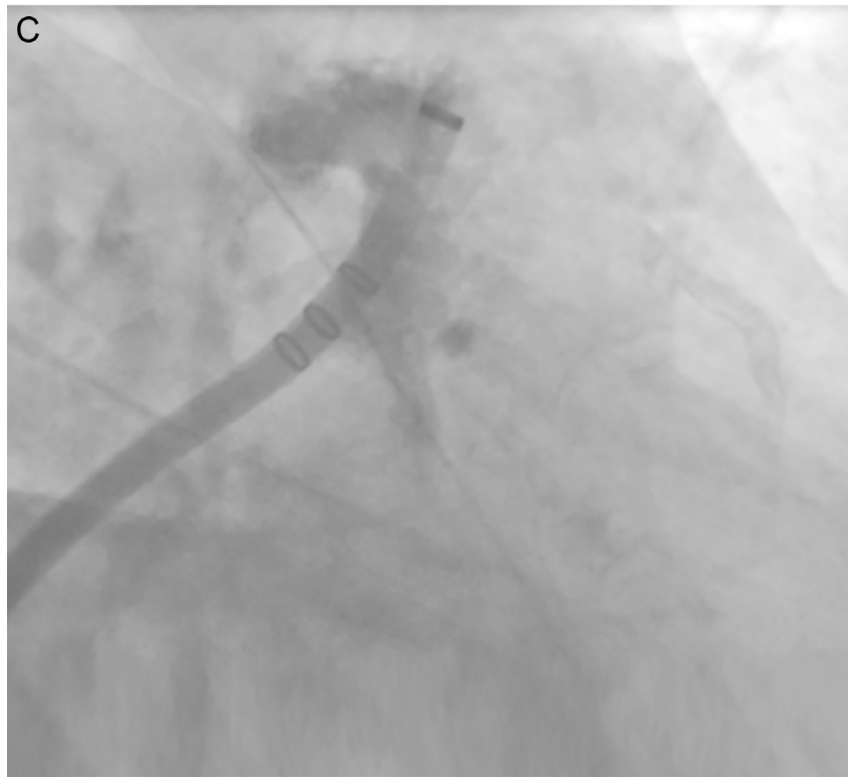

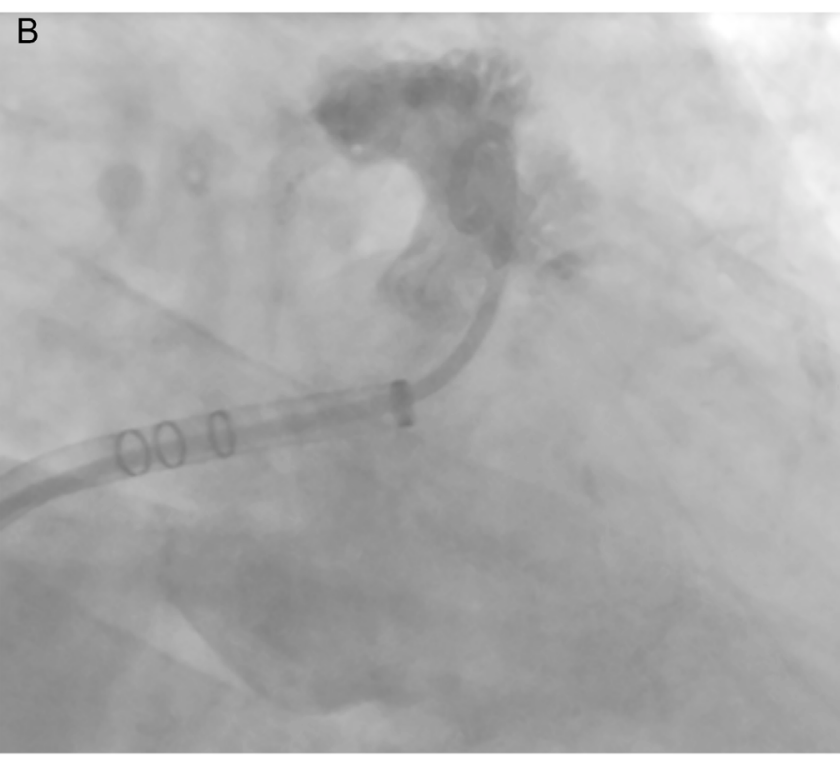

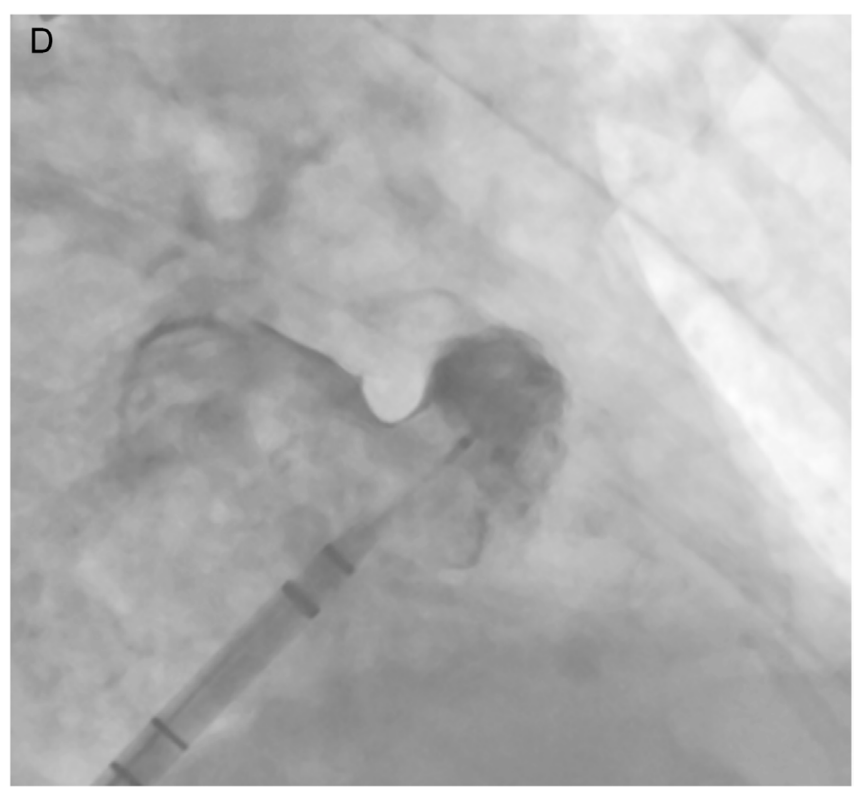

Figure 2. Panel A. WATCHMAN device. The WATCHMAN device consists of a self-expanding nitinol frame with fixation barbs. There is a porous polyethylene terephthalate membrane on the face of the device which endothelializes over time occluding the ostium of the appendage (image courtesy of Boston Scientific, Inc.). Panel B. Left atrial appendage (LAA) with pigtail catheter in place. A pigtail catheter is utilized to cannulate the LAA in an atraumatic fashion. Angiography of the LAA is performed to gain an understanding of the anatomy. The WATCHMAN 14 French sheath is placed over the pigtail into the LAA. PanelC. LAA with WATCHMAN sheath. The pigtail catheter is removed and the WATCHMAN 14 French access sheath is carefully maneuvered distally into the LAA. Marker bands which are visible under fluoroscopy allow for determination of where the device will land when access sheath is removed and device unsheathed. Panel D. LAA with WATCHMAN deployed. The device is loaded into the distal sheath and unsheathed with removal of the access sheath while maintaining distal position of the WATCHMAN device within the LAA. The device is secured in position with fixation barbs present along the sides of the device which engage the endocardium.

farin was discontinued in those patients who either had complete closure of the LAA or a small peridevice leak (jet $<5 \mathrm{~mm}$ in width). After discontinuation of warfarin, aspirin (81-325 mg) was continued with the addition of plavix $(75 \mathrm{mg})$ until the 6-month follow up. At this point, plavix was discontinued. Aspirin 

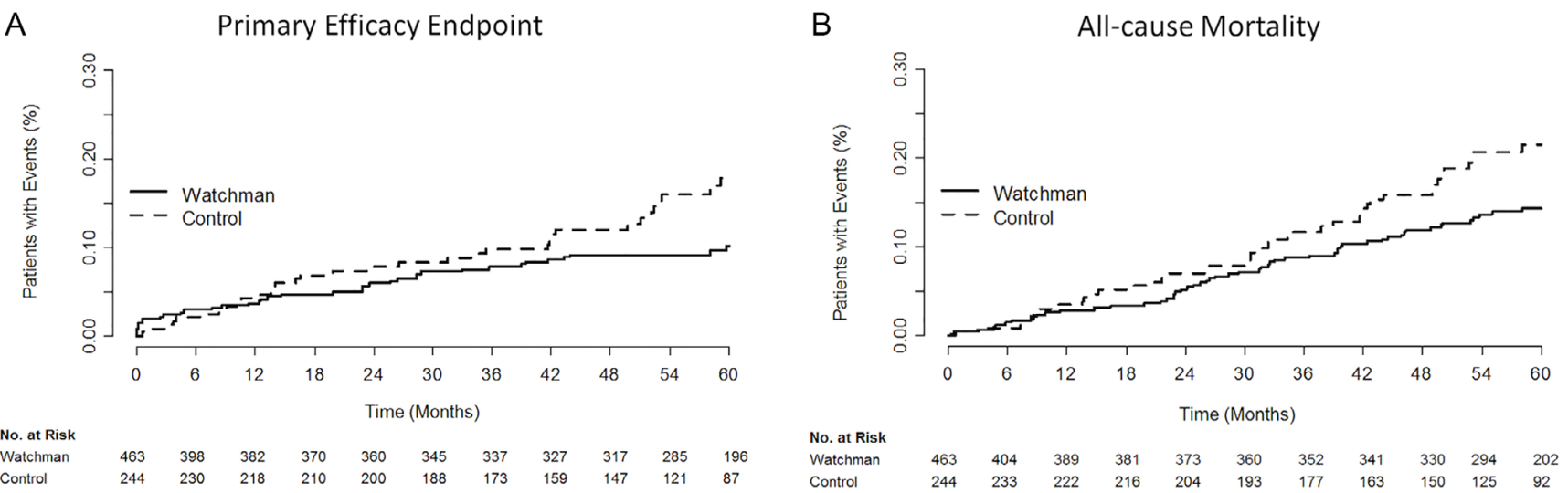

Figure 3. WATCHMAN efficacy data (PROTECT AF). Panel A. Primary efficacy. At 2621 patient-years of follow up, the WATCHMAN device met criterion for superiority compared to warfarin therapy for the combined endpoint of cardiovascular/unexplained death, stroke, or systemic embolism (2.3 events per 100 patient-years versus 3.8 per 100 patient years; RR 0.6; $95 \%$ Crl 0.41 to 1.05; posterior probability of 96\%) [45]. Panel B. All-cause mortality. At 2621 patient-years of follow up, the WATCHMAN device was superior with regard to all-cause mortality (3.2\% versus 4.8\%; RR 0.66; 95\% Crl, 0.45 to 0.98 ) and cardiovascular mortality (1 per 100 patient years versus 2.4 per 100 patient-years; RR 0.4; 95\% Crl, 0.21 to 0.72) compared with warfarin [45].

alone was continued thereafter.

The initial 1065 patient-years follow-up demonstrated WATCHMAN as noninferior to warfarin for the combined efficacy primary endpoint of cardiovascular/unexplained death, stroke, or systemic embolism. The primary efficacy endpoint event rate was 3.0 per 100 patient-years (95\% credible interval [Crl] 1.9-4.5) in the WATCHMAN group and 4.9 per 100 patient-years $(95 \% \mathrm{Crl} 2.8-7.1)$ in the warfarin group (rate ratio [RR] 0.62, 95\% Crl 0.35-1.25). Analysis at 1588 patient-years confirmed the noninferiority of WATCHMAN compared to warfarin with regard to the primary efficacy endpoint of cardiovascular/ unexplained death, stroke, or systemic embolism (RR $0.71,95 \% \mathrm{Crl} 0.44$ to 1.30 ) [44]. At 2621 patient-years of follow up, the WATCHMAN device met criterion for superiority compared to warfarin therapy for the combined endpoint ( 2.3 events per 100 patient-years versus 3.8 per 100 patient years; RR 0.6; 95\% Crl 0.41 to 1.05; posterior probability of $96 \%$ ) [45]. Additionally, the WATCHMAN device was superior with regard to all-cause mortality (3.2\% versus $4.8 \%$; RR 0.66 ; $95 \% \mathrm{Crl}, 0.45$ to 0.98 ) and cardiovascular mortality (1 per 100 patientyears versus 2.4 per 100 patient-years; RR $0.4 ; 95 \% \mathrm{Crl}, 0.21$ to 0.72 ) compared with warfarin (Figure 3). Hemorrhagic stroke rates were significantly lower in the WATCHMAN group $(0.2 \%$ versus $1 \%$; RR $0.18 ; 95 \% \mathrm{Crl}, 0.04$ to 0.6$)$.
The PROTECT AF study demonstrated that the WATCHMAN device could be successfully implanted. It was successfully implanted in $88 \%(408 / 463)$ of patients randomized to the WATCHMAN group and in $91 \%$ (408/449) of patients in whom implant was attempted. At the 45-day TEE, 86\% (349/408) of patients were able to discontinue warfarin. At the 6-month TEE, 92\% (355/408) of patients were able to discontinue warfarin. While long-term follow up of PROTECT AF has demonstrated sustained efficacy and confirmed long-term safety, acute safety events in PROTECT AF were an initial concern. Primary safety events at 18 months occurred at a higher rate in the WATCHMAN group compared to the warfarin group (RR 1.69, 95\% Crl 1.01-3.19). The majority of safety events in the WATCHMAN group (55\%, 27out of 49 ) occurred on the day of the procedure. This contrasts to the warfarin group, which had half (8 out of 16) occur between day 45 and 1 year. The most frequent primary complications were directly procedure related including serious pericardial effusion and procedure-related ischemic stroke. No peri-procedural death or long-term disability occurred within this or in any WATCHMAN clinical trial. In further analysis, there was a significant decline in procedure related safety events within 7 days of the procedure between the first and second halves of the PROTECT AF trial and the Continued Access Protocol Registry (CAP) 
[46]. This suggested a significant improvement in safety with operator experience and technical refinement of the procedure.

The Prospective Randomized Evaluation of the Watchman Left Atrial Appendage Closure Device in Patients With Atrial Fibrillation Versus Long-Term Warfarin Therapy (PREVAIL) trial was the second randomized, controlled trial conducted to further evaluate safety and efficacy with the WATCHMAN device in response to U.S. Food and Drug Administration concerns over selection criteria and acute safety events [47]. The PREVAIL trial randomized patients 18 years old or older with nonvalvular AF with a $\mathrm{CHADS}_{2}$ score greater than or equal to 2 or 1 with an additional high-risk characteristic (female age $\geq 75$ years, baseline ejection fraction $\geq 30$ but $<$ $35 \%$, age 65 to 74 years and either diabetes or coronary disease, and age $\geq 65$ years old with congestive heart failure). This was meant to include higher risk patients than were evaluated in PROTECT AF. A total of 407 patients were randomized in a 2:1 fashion with 269 patients in the WATCHMAN group and 138 patients in the warfarin group. The WATCHMAN device was successfully implanted in $95.1 \%$ of patients in whom implant was attempted, an improvement from PROTECT AF ( $p=0.04)$. Furthermore, $39.1 \%$ of implants were performed by new implanters with no statistically significant difference in success or in complications compared to experienced implanters demonstrating improvements in physician education and the evolution of the procedure. All 7-day complications after attempted implantation including pericardial effusion requiring surgery, pericardial effusion requiring pericardiocentesis, procedure-related strokes, and device embolization occurred at significantly lower rate in PREVAIL compared to PROTECT AF (4.5\% versus $8.7 \%, p=0.004)$. This data was consistent with data from CAP registry demonstrating procedural complications as infrequent and significantly improved (Figure 4).

The PREVAIL composite 18 month efficacy endpoint (stroke, systemic embolization, and cardiovascular/unexplained death) failed to achieve the noninferiority prespecified criteria. Event rates in the WATCHMAN arm and the warfarin arm were similar (0.064 versus 0.063 ). The 18-month rate ratio of $1.07 \mathrm{had}$ a $95 \% \mathrm{Crl}$ of 0.57 to 1.89 , which failed to meet the prespecified upper bound

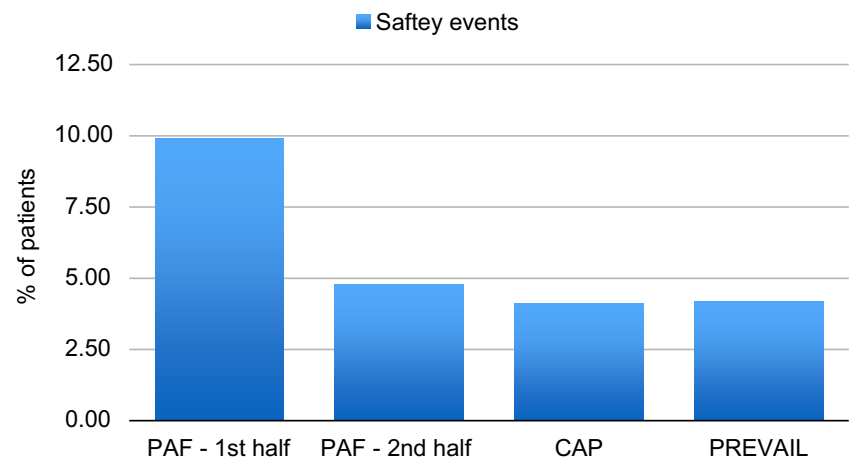

Figure 4. WATCHMAN safety events: PROTECT AF(PAF), Continued Access Protocol Registry (CAP), Prospective Randomized Evaluation of the Watchman Left Atrial Appendage Closure Device in Patients With Atrial Fibrillation Versus Long-Term Warfarin Therapy (PREVAIL). Safety data from PROTECT AF and CAP registry were compared by Reddy et al. [45]. Results of PREVAIL [47] demonstrated consistent reduction in safety events. All 7-day complications after attempted implantation including pericardial effusion requiring surgery, pericardial effusion requiring pericardiocentesis, procedure related strokes, and device embolization occurred at significantly lower rate in PREVAIL compared to PROTECT AF (4.5\% versus $8.7 \%, p=0.004$ ).

of 1.75. The rate of stroke after 7 days after randomization was 0.0253 in the WATCHMAN arm and 0.0273 in the warfarin arm meeting prespecified criteria for noninferiority. Importantly, the warfarin arm ischemic stroke rate per patient years in PREVAIL (0.70) was significantly lower than all other recent AF studies involving NOACs [i.e. RE-LY (1.7) [13], ARISTOTLE (1.6) [14], and ROCKET AF (2.2) [15]].

While PROTECT AF, CAP, and PREVAIL included warfarin eligible patients, the group in most need of alternatives to anticoagulation include those nonvalvular AF patients who are unable to be treated with anticoagulation. While there are no randomized trial data, the ASA Plavix Registry (ASAP) study evaluated such patients [48]. A total of 150 nonvalvular AF patients who were ineligible for warfarin were prospectively enrolled in this observational study. Prior bleeding was the main reason for inability to be treated with warfarin. Patients were placed on with clopidogrel for 6 months after implantation of the WATCHMAN device and with aspirin indefinitely thereafter. Patients were followed up for a mean of $14.4 \pm 8.6$ months. The observed event rate for stroke or systemic embolism was $2.3 \%$ per year. The expected event rate based 
on a mean $\mathrm{CHADS}_{2}$ score of 2.8 was $7.3 \%$ per year. This demonstrated an association with significant event rate reduction. Of note, laminar thrombus formation has been reported with the WATCHMAN device. The ASAP trial had six cases of thrombus formation (4\%) on the device with only one resultant clinical event (ischemic stroke). This was similar to PROTECT AF, which had a $4.2 \%$ (20 of 473) thrombus formation rate with three having ischemic strokes. The thrombus-associated annualized stroke rate was $0.3 \%$. While ASAP was a prospective, observational trial, the totality of data involving the WATCHMAN device remains critical to establishing the LAA as focal source of thromboembolus and that closure of the LAA decreases stroke rate. Data from various studies support WATCHMAN as an alternative to anticoagulation in both warfarin eligible and warfarin ineligible patients.

\section{Lariat}

The Lariat device (SentreHeart, Redwood City, California, USA) is a transcatheter LAA ligation system that utilizes both endocardial and epicardial approach to place a preformed surgical knot around the ostium of the LAA and approximate all walls thus excluding the LAA [49]. Epicardial access ("dry tap") is performed through a subxyphoid approach with a micropuncture needle or 17-gauge epidural needle. Access is obtained in the anterior aspect of the pericardial sac with angulation toward the LAA. Dilation up to a 14 French sheath is required. The 14 French epicardial sheath is placed over a stiff guidewire. Femoral venous access is obtained and a transseptal puncture is performed to gain left atrial access. A magnet tip wire is then placed in the LAA endocardially. An epicardial magnet wire is advanced into the pericardial space toward the LAA until a connection is made between the endo- and epi-magnet wires. The Lariat loop snare is then carefully advanced over the epicardial wire while holding the wires in place until the device is placed over the LAA and closed (Figure 5). TEE guidance is utilized to visualize LAA closure and assess adequacy of closure. A preformed surgical knot is deployed. A tensioner is used to tighten the knot before cutting the suture. The procedure

Journal of Structural Heart Disease, February 2016 is limited to patients with LAA less than $40 \mathrm{~mm}$ due to loop snare size. Unfavorable orientation of the appendage determined on the required preoperative CT may exclude the patient from this procedure. It is also limited to patients who have not had previous cardiac surgery. The device currently has FDA 510k approval for tissue approximation. While initial data has demonstrated a high rate of success in terms of closure and leaks, most studies have been small, observational studies. Bartus et al. [49] prospectively enrolled 92 patients who were not warfarin eligible or were poor candidates for warfarin. Presence of pericardial adhesions excluded three patients. The remaining 89 patients underwent attempted Lariat closure of the LAA. Successful closure $(<1 \mathrm{~mm}$ residual leak) was performed in $96 \%$ of the patients. Of patients undergoing TEE at one year, $98 \%$ (64 of 65 ) had complete closure. Complications occurred in five patients with three having pericardial effusions and two having pericarditis. An additional patient developed a late effusion, 2 weeks after LAA closure. More recently, Price et al. [50] retrospectively evaluated the results of Lariat procedures in 154 patients at eight different centers. While procedural success was high (86\%), major complications occurred in 15 patients (9.7\%). Significant pericardial effusion occurred in 16 patients (10.4\%). There were $14(9.1 \%)$ major bleeds with $4.5 \%$ of all patients needing transfusion. Death, myocardial infarction, or stroke occurred in 4 patients (2.9\%). Thrombus formation at the endocardial site of LAA closure has also been reported [51, 52]. Given the limited data, a large, randomized, controlled trial is needed not only to confirm the apparent high procedural success but also better understand the clinical efficacy of the procedure as well as the procedural risks involved with this technique.

\section{Wavecrest}

The Wavecrest LAA occluder device (Coherex Medical, Salt Lake City, Utah, USA) is an umbrella shaped device designed to cover the LAA at the ostium. It is constructed with a nitinol frame and covering material with anchoring barbs which are deployed after the covering face is first positioned into place at the osmium (Figure 6). The covering material consists of nonpermeable, Teflon material at the face and a foam 

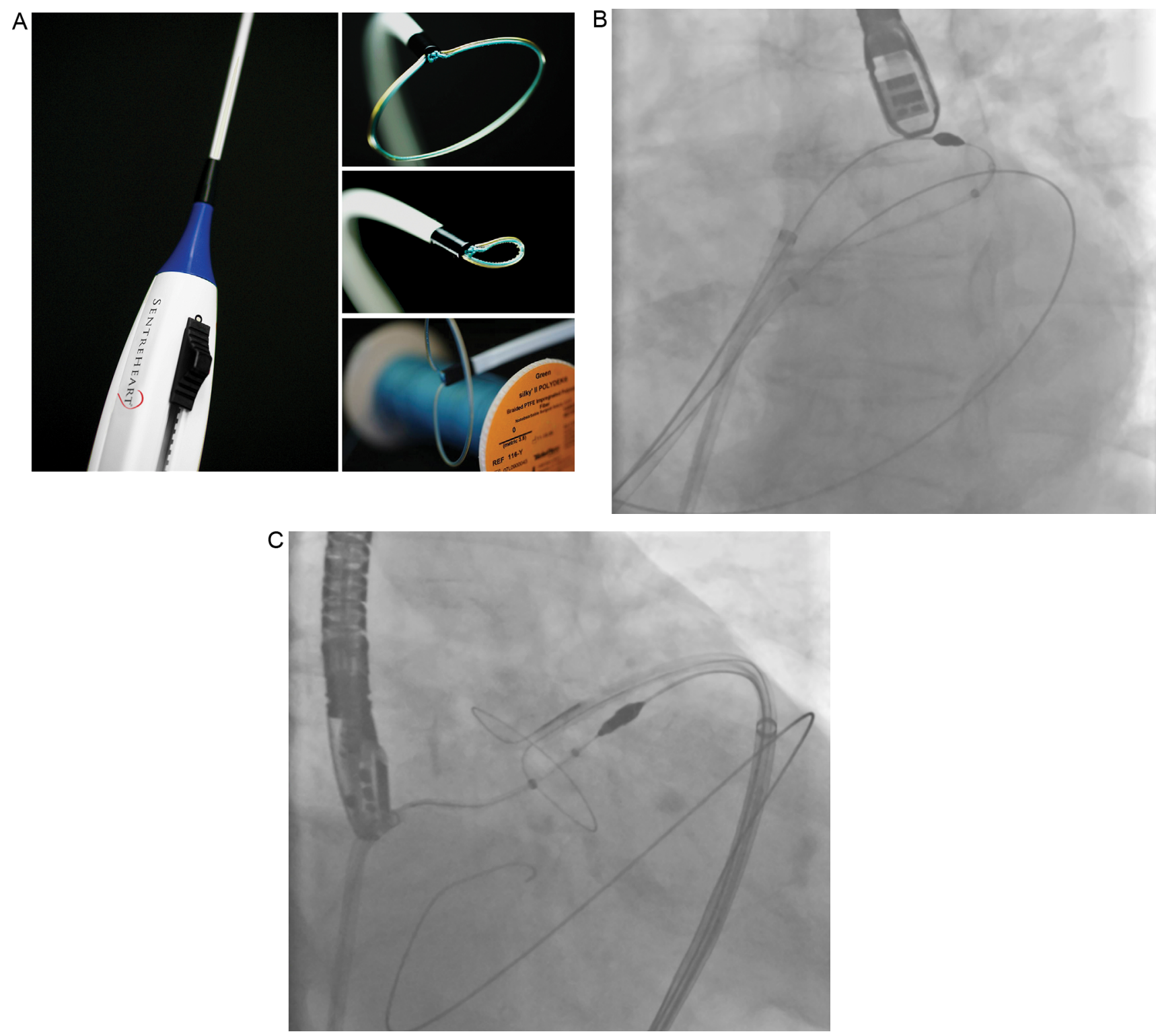

Figure 5. Panel A. LARIAT image courtesy of SentreHeart, Inc. Panel B. This left anterior oblique projection demonstrates epicardial and endocardial magnet wires connected at the tip of the left atrial appendage (LAA). An additional wire for maintained pericardial access is also seen. Panel $C$. This right anterior oblique fluoroscopy image demonstrates the LARIAT snare being placed over the appendage while the endocardial and epicardial magnet wires function as a rail. Once over the base of the LAA, the snare will be closed.

cuff around the face for direct contact with the endocardium. The device is delivered through the femoral vein into the left atrium via trans-septal access and requires fluoroscopy and TEE guidance as with other LAA occluder devices. The Wavecrest device differs from others in that the occluding atraumatic face of the device is deployed first into the LAA at the ostium and advanced outside of the delivery sheath without requiring delivery sheath placement into the
LAA itself. Once in position, the deployment anchors are advanced into the LAA body. Currently, dual antiplatelet therapy is recommended after implantation. This device has received CE mark approval. There is limited data concerning clinical outcomes with this device at this time. 


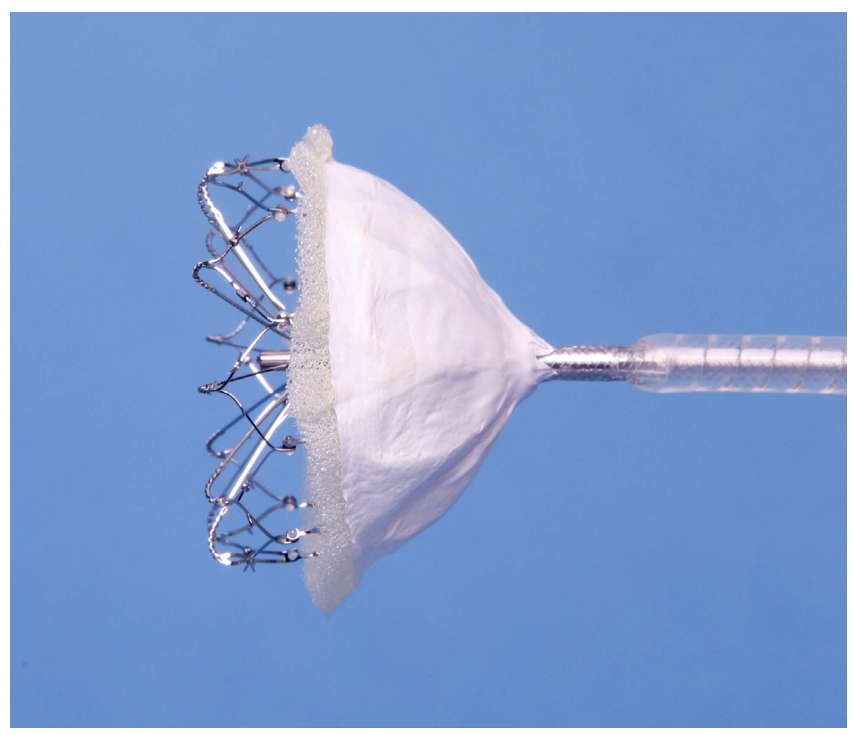

Figure 6. WAVECREST. The Wavecrest is an umbrella shaped device constructed with a nitinol frame and covering material with anchoring barbs which are deployed after the covering face is first positioned into place at the ostium. The covering material consists of non-permeable, Teflon material at the face, and a foam cuff around the face for direct contact with the endocardium (image courtesy of Coherex Medical, Inc.).

\section{Discussion}

Percutaneous transcatheter LAA closure provides an alternative in the treatment of patients with nonvalvular AF at high risk for stroke. Warfarin alone has been the mainstay of therapy until recently with the introduction of NOAC agents. While these agents provide some advantages over warfarin, they are not without risk of bleeding. While risk of intracranial bleeding is less with these agents, overall risk of bleeding is similar to warfarin with the exception of apixaban. Gastrointestinal bleeding is higher with both dabigatran and rivaroxaban compared with warfarin $[13,15]$. Currently, there are no approved antidotes for these agents presenting challenges for management. These agents also do not fully address the issue of noncompliance and intolerance with significant discontinuation rates of all oral anticoagulants. Currently, the European Society of Cardiology guidelines for the management of atrial fibrillation support consideration of transcatheter closure of the LAA in patients with a high stroke risk and contraindications for long-term oral anticoagulation [53]. The American Heart Association/American College of

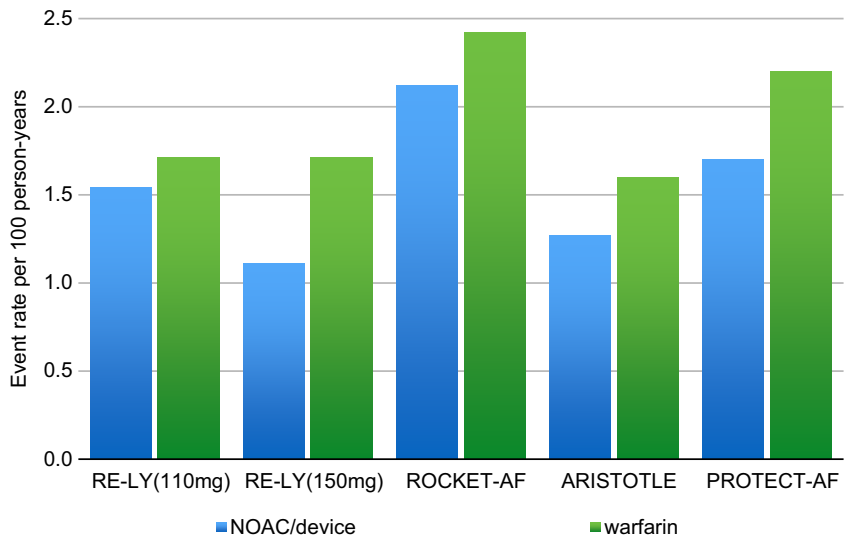

Figure 7. Comparison of stroke or systemic embolism event rate per 100 person-years. RE-LY [13], ARISTOTLE [14], ROCKET-AF [15], and PROTECT AF [45] trials demonstrating event rates of stroke or systemic embolism per 100 person-years.

Cardiology/Heart Rhythm Society guidelines for the management of patients with atrial fibrillation discuss percutaneous LAA closure but do not provide any recommendations with regard to its use [54]. Though WATCHMAN has demonstrated noninferiority and superiority compared to warfarin eligible patients, no direct comparison to NOACs is currently available. Indirect comparisons of relative reduction in mortality between NOACs and WATCHMAN compared to warfarin favor LAA closure with WATCHMAN (Figure 7). Indirect comparisons with regard to stroke rate or rate of systemic embolism also appear similar (Figure 8). The debate continues whether the WATCHMAN device should be used as alternative to anticoagulation as in PROTECT AF, CAP and PREVAIL trials or indicated only for those patients with relative or absolute contraindications to anticoagulation as in ASAP. There is a paucity of data with other devices with no other randomized trial data to support LAA closure as an alternative to anticoagulation with such devices at this time. Such devices should be limited to patients with contraindications to anticoagulation until further data are available.

The patients who stand to benefit most from LAA closure include those at highest risk for bleeding. Interestingly, these patients are also at the highest risk of thromboembolic stroke. Continued understanding of risks of transcatheter LAA closure techniques is needed to allow for more accurate risk assessment for patients facing the choice of being at high risk for bleeding com- 


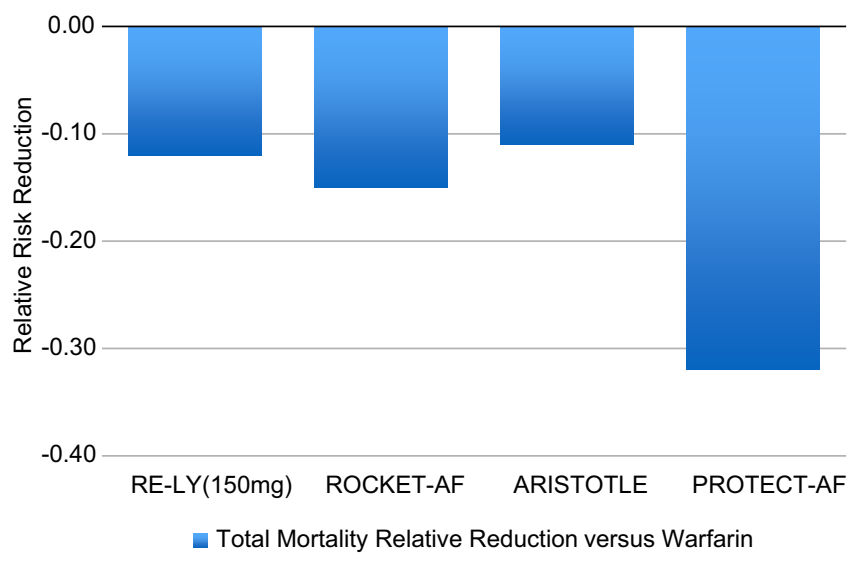

Figure 8. Indirect comparison of total mortality reduction from major trials. RE-LY [13], ARISTOTLE [14], ROCKET-AF [15], and PROTECT AF [45] trials demonstrating relative risk reduction in total mortality.

plications, at high risk for thromboembolic stroke, or at risk of complications from a percutaneous procedure. Tools such as $\mathrm{CHA}_{2} \mathrm{DS}_{2}$ VASc score allow for such determination of CVA risk in nonvalvular AF patients. Assessment of bleeding risk is equally important. The HASBLED score [55] has been validated and can be used to determine risk of bleeding among patients who have an indication for anticoagulation (Table 2). The risk of each individual transcatheter technique must be established to accurately determine at what point LAA closure is indicated and the risks acceptable. Consideration of both procedure risks and long-term risks of the device themselves must be evaluated. It is important to note that bleeding and stroke risk continue yearly with life-long anticoagulation, while procedural risks of device implantation are usually short term and should be weighed as such. None the less, there is a large population of patients at this time in need of alternatives especially those with relative and absolute contraindications to anticoagulation use who are also at high risk of thromboembolic stroke from AF.

\section{Conclusion}

LAA closure is a rapidly developing area of cardiology with significant promise. Transcatheter LAA occlusion has shown that local therapy can reduce systemic
Table 2: HAS-BLED

\begin{tabular}{ll}
\hline HAS-BLED & Score \\
\hline Hypertension (systolic blood pressure > 160 mm Hg) & 1 \\
Abnormal renal and liver function (1 point each) & 1 or 2 \\
Stroke & 1 \\
Bleeding tendency/predisposition & 1 \\
Labile INRs (if on warfarin) & 1 \\
Elderly (age > 65 years) & 1 \\
Drugs or alcohol (1 point each) & 1 or 2 \\
Maximum score & 9 \\
\hline
\end{tabular}

thromboembolism. The individual techniques and devices involved require continued prospective study to demonstrate each device's efficacy and safety as well as to determine specific anticoagulation or antiplatelet regimens that may or may not be necessary. While data from the only randomized, controlled, trials available compared LAA closure to anticoagulation eligible patients, it is likely that this technology will be limited until further confirmatory data are available. It is clear that a large percentage of patients are currently unable to be treated with oral anticoagulation of any kind. Another option is needed for patients. Further study may expand the indications as technologies continue to develop and more data are available.

\section{Conflict of Interest}

Sánchez reports having received consulting fees from Boston Scientific, the manufacturer of the Watchman device. Dr. Holmes has received research grant support from Atritech/Boston Scientific. In addition, the Watchman LAA closure technology has been licensed to Atritech, and both Mayo Clinic and David Holmes have contractual rights to receive future royalties from this license. To date, no royalties have been received.

\section{Comment on this Article or Ask a Question}




\section{References}

1. Go AS, Hylek EM, Phillips KA, et al. Prevalence of diagnosed atrial fibrillation in adults: national implications for rhythm management and stroke prevention: The AnTicoagulation and Risk Factors in Atrial Fibrillation (ATRIA) Study. JAMA. 2001;285:2370-2375. DOI: 10.1001/jama. 285.18.2370

2. Thom T, Haasne N, Rosamond W, et al. Heart disease and stroke statistics -2006 update: A report from the American Heart Association Statistics Committee and Stroke Statistics Committee. Circulation. 2006; 113:e85-151. DOI: 10.1161/CIRCULATIONAHA.105.171600

3. Feinburg WM, Blackshear JL, Laupacis $A$, et al. Prevalence, age distribution, and gender of patients with atrial fibrillation. Analysis and implications. Arch Intern Med. 1995;155:469-473. DOI: 10.1001/ archinte.1995.00430050045005

4. Miyasaka Y, Barnes ME, Gersh BJ, et al. Secular trends in incidence of atrial fibrillation in Olmsted County, Minnesota, 1980 to 2000, and implications on the projections for future prevalence. Circulation. 2006; 114:119-125. DOI: 10.1161/CIRCULATIONAHA.105.595140

5. Wang TJ, Larson MG, Levy D, et al. Temporal relations of atrial fibrillation and congestive heart failure and their joint influence on mortality: the Framingham Heart Study. Circulation. 2003;107:29202925. DOI: 10.1161/01.CIR.0000072767. 89944.6E

6. Ott $A$, Breteler $M M$, de Bruyne $M C$, et al. Atrial fibrillation and dementia in a population-based study. The Rotterdam Study. Stroke. 1997;28:316-321. DOI: 10.1161/01. STR.28.2.316

7. Kannel WB, Wolf PA, Benjamin EJ, et al. Prevalence, incidence, prognosis, and predisposing conditions for atrial fibrillation: population-based estimates. Am J Cardiol. 1998;82:2N-9N. DOI: 10.1016/S00029149(98)00583-9

8. Wolf PA, Abbott RD, Kannel WB. Atrial fibrillation: A major contributor to stroke in the elderly. The Framingham Study. Arch Intern Med. 1987;147:1561-1564. DOI: 10.1001/archinte.147.9.1561

9. Miller PS, Andersson FL, Kalra L. Are cost benefits of anticoagulation for stroke prevention in atrial fibrillation underestimated? Stroke. 2005;36:360-366. DOI: 10.1161/01. STR.0000153002.56324.8c

10. Hart RG, Pearce LA, Aguilar MI. Meta-analysis: antithrombotic therapy to prevent stroke in patients who have nonvalvular atrial fibrillation. Ann Intern Med. 2007; 146:857-867. DOI: 10.7326/0003-4819-14612-200706190-00007

11. Waldo AL, Becker RC, Tapson VF, Colgan KJ. Hospitalized patients with atrial fibrillation and a high risk of stroke are not being provided with adequate anticoagulation. J Am Coll Cardiol. 2005;46:1729-1736. DOI: 10.1016/j.jacc.2005.06.077

12. Hylek EM, Evans-Molina C, Shea C, Henault $\mathrm{LE}$, Regan S. Major hemorrhage and tolerability of warfarin in the first year of therapy among elderly patients with atrial fibrillation. Circulation. 2007;115:2689-2696. DOI: 10.1161/CIRCULATIONAHA.106.653048

13. Connolly SJ, Ezekowitz MD, Yusuf S, et al. Dabigatran versus warfarin in patients with atrial fibrillation. N Engl J Med. 2009; 361:1139-1151. DOI: 10.1056/NEJMoa 0905561

14. Granger CB, Alexander JH, McMurray $J J$, et al. Apixaban versus warfarin in patients with atrial fibrillation. N Engl J Med. 2011;365:981-992. DOI: 10.1056/NEJMoa 1107039

15. Patel MR, Mahaffey KW, Garg J, et al. Rivaroxaban versus warfarin in nonvalvular atrial fibrillation. N Engl J Med. 2011;365:883891. DOI: 10.1056/NEJMoa1009638

16. Blackshear JL, Odell JA. Appendage obliteration to reduce stroke in cardiac surgical patients with atrial fibrillation. Ann Thorac Surg. 1996;61(2):755-759. DOI: 10.1016/0003-4975(95)00887-X

17. Zabalgoita $M$, Halperin JL, Pearce LA, Blackshear JL, Asinger RW, Hart RG. Transesophageal echocardiographic correlates of clinical risk of thromboembolism in nonvalvular atrial fibrillation: Stroke Prevention in Atrial Fibrillation III Investigators. J Am Coll Cardiol. 1998;31:1622-1626. DOI: 10.1016/S0735-1097(98)00146-6

18. Khurram IM1, Dewire J, Mager $M$, Maqbool F, Zimmerman SL, Zipunnikov $V$, et al. Relationship between left atrial appendage morphology and stroke in patients with atrial fibrillation. Heart Rhythm. 2013;10(12):1843-1849. DOI: 10.1016/j.hrthm.2013.09.065

19. Di Biase L1, Santangeli P, Anselmino $M$, Mohanty $P$, Salvetti I, Gili S, et al. Does the left atrial appendage morphology correlate with the risk of stroke in patients with atrial fibrillation? Results from a multicenter study. J Am Coll Cardiol. 2012;60(6):531-538. DOI: 10.1016/j. jacc.2012.04.032
20. Conway D, Pearce LA, Chin PB, Hart RG, Lip G. Plasma von Willebrand factor and soluble $p$-selectin as indices of endothelial damage and platelet activation in 1321 patients with nonvalvular atrial fibrillation: Relationship to stroke risk factors. Circulation. 2002;106:1962-1967. DOI: 10.1161/01.CIR.0000033220.97592.9A

21. Lip G, Patel JV, Hughes E, Hart RG. Highsensitivity C-reactive protein and soluble CD40 ligand as indices of inflammation and platelet activation in 880 patients with nonvalvular atrial fibrillation: Relationship to stroke risk factors, stroke risk stratification schema, and prognosis. Stroke. 2007; 38:1227-1237. DOI: 10.1161/01.STR. $0000260090.90508 .3 e$

22. January CT, Wann LS, Alpert JS, Calkins $\mathrm{H}$, Cleveland JC Jr, Cigarroa JE, et al. 2014 AHA/ACC/HRS Guideline for the management of patients with atrial fibrillation: Executive Summary: A report of the American College of Cardiology/American Heart Association Task Force on Practice Guidelines and the Heart Rhythm Society. Circulation. 2014; Apr 10.

23. Madden JL. Resection of the left auricular appendix: A prophylactic for recurrent arterial emboli. J Am Med Assoc. 1949;140:769-772. DOI: 10.1001/jama. 1949.02900440011003

24. Kanderian AS1, Gillinov AM, Pettersson GB, Blackstone $\mathrm{E}$, Klein AL. Success of surgical left atrial appendage closure: assessment by transesophageal echocardiography. J Am Coll Cardiol. 2008; 52(11):924-929. DOI: 10.1016/j.jacc.2008. 03.067

25. Wolf RK1, Schneeberger EW, Osterday R, Miller D, Merrill W, Flege JB Jr, et al. Video-assisted bilateral pulmonary vein isolation and left atrial appendage exclusion for atrial fibrillation. J Thorac Cardiovasc Surg. 2005;130(3):797-802. DOI: 10.1016/j.jtcvs.2005.03.041

26. Johnson WD, Ganjoo AK, Stone CD, Srivyas RC, Howard M. The left atrial appendage: our most lethal human attachment! Surgical implications. Eur J Cardiothorac Surg. 2000;17:718-722. DOI: 10.1016/S10107940(00)00419-X

27. Ohtsuka T, Nimomiya $M$, Nonaka $T$, Hisagi M, Ota T, Mizutani T. Thoracoscopic stand-alone left atrial appendectomy for thromboembolism prevention in nonvalvular atrial fibrillation. J Am Coll Cardiol. 2013; 62:103-107. DOI: 10.1016/j. jacc.2013.01.017 
28. Ailawadi G1, Gerdisch MW, Harvey RL, Hooker RL, Damiano RJ Jr, Salamon T, et al. Exclusion of the left atrial appendage with a novel device: early results of a multicenter trial. J Thorac Cardiovasc Surg. 2011;142(5):1002-1009. DOI: 10.1016/j. jtcvs.2011.07.052

29. Slater AD, Tatooles AJ, Coffey A, Pappas PS, Bresticker M, Greason K, et al. Prospective clinical study of a novel left atrial appendage occlusion device. Ann Thorac Surg. 2012; 93:1887-1889. DOI: 10.1016/j.athoracsur.2011.12.077

30. Benussi S, Mazzone P, Maccabelli G, Vergara $P$, Grimaldi A, Pozzoli A, et al. Thoracoscopic appendage exclusion with an AtriClip device as a solo treatment for focal atrial tachycardia. Circulation. 2011;123:1575-1578. DOI: 10.1161/CIRCULATIONAHA.110.005652

31. Sievert $H$, Lesh $M$, Trepels $T$, Omran $H$, Bartorelli A, Della Bella P, et al. Percutaneous left atrial appendage transcatheter occlusion to prevent stroke in high-risk patients with atrial fibrillation: Early clinical experience. Circulation. 2002;105:1887-1889. DOI: 10.1161/01.CIR.0000015698.54752.6D

32. Block PC, Burstein S, Casale PN, Kramer PH, Teirstein P, Williams DO, et al. Percutaneous left atrial appendage occlusion for patients in atrial fibrillation suboptimal for warfarin therapy: 5-Year results of the PLAATO (Percutaneous Left Atrial Appendage Transcatheter Occlusion) study. J Am Coll Cardiol Interv. 2009;2:594-600. DOI: 10.1016/j. jcin.2009.05.005

33. Bayard $Y$, Omran $H$, Kramer $P$, Matthews $R$, Reisman $M$, Block $P$, et al. Worldwide experience of percutaneous left atrial appendage transcatheter occlusion (PLAATO). J Neurol Sci. 2005;238:S70-S70. DOI: 10.1016/S0022-510X(05)80271-0

34. Park JW, Bethencour $A$, Sievert $H$, Santoro G, Meier B, Walsh K, et al. Left atrial appendage closure with Amplatzer cardiac plug in AF. Initial European experience. Catheter Cardiovasc Interv. 2011;77:700706. DOI: $10.1002 / \mathrm{ccd} .22764$

35. Lam YY, Yip W, Yu CM, et al. Left atrial appendage closure with AMPLATZER cardiac plug for stroke prevention in atrial fibrillation: initial Asia-Pacific experience. Catheter Cardiovasc Interv. 2012;79:794-780. DOI: $10.1002 / \mathrm{ccd} .23136$

36. Urena M, Rodés-Cabau J, Freixa $X$, Saw J, Webb JG, Freeman M, et al. Percutaneous Left Atrial Appendage Closure With the AMPLATZER Cardiac plug device in patients with nonvalvular atrial fibrillation and contraindications to anticoagula- tion therapy. J Am Coll Cardiol. 2013;62: 96-102. DOI: 10.1016/j.jacc.2013.02.089

37. Cruz-Gonzalez I, Moreiras J, Garcia E. Thrombus formation after left atrial appendage exclusion using an Amplatzer cardiac plug device. Catheter Cardiovasc Interv. 2011;78: 970-973. DOI: $10.1002 / \mathrm{ccd} .23126$

38. Cardona L, Galrinho A, Luisa B, Leal A, Antonio F, Lidia $S$, Cruz F. Thrombus formation on a left atrial appendage closure device. Circulation. 2011; 124:1595-1596. DOI: 10.1161/CIRCULATIONAHA.110.004135

39. Plicht B, Konorza TFM, Kahlert P, Al-Rashid $F$, Kaelsch $H$, Jánosi RA, et al. Risk factors for thrombus formation on the amplatzer cardiac plug after left atrial appendage occlusion. J Am Coll Cardiol Intv. 2013; 6:606-613. DOI: 10.1016/j.jcin.2013.02.014

40. Freixa X, Chan JL, Tzikas A, Garceau P, Basmadjian A, Ibrahim R. The Amplatzer TM Cardiac Plug 2 for left atrial appendage occlusion: novel features and first-in-man experience. Eurolntervention. 2013;8: 1094-1098. DOI: 10.4244/EIJV8I9A167

41. AMPLATZER cardiac plug clinical trial. Available at: http://clinicaltrials.gov/ ct2/show/record/NCT01118299?ter$\mathrm{m}=\mathrm{LAA}+\mathrm{ACP} \& \mathrm{rank}=3$

42. Holmes DR, Reddy VY, Turi ZG, Soshi SK, Sievert $H$, Buchbinder $M$, et al. Percutaneous closure of the left atrial appendage versus warfarin therapy for prevention of stroke in patients with atrial fibrillation: $A$ randomized non-inferiority trial. Lancet. 2009;374: 534-542. DOI: 10.1016/501406736(09)61343-X

43. Gage BF, Waterman AD, Shannon W, et al. Validation of clinical classification schemes for predicting stroke. Results from the National Registry of Atrial Fibrillation. JAMA. 2001; 285:2864-2870. DOI: 10.1001/ jama.285.22.2864

44. Reddy VY, Doshi SK, Sievert H, Buchbinder M, Neuzil P, Huber K, et al. Percutaneous left atrial appendage closure for stroke prophylaxis in patients with atrial fibrillation: 2.3-year follow-up of the PROTECT AF (Watchman Left Atrial Appendage System for Embolic Protection in Patients With Atrial Fibrillation) Trial. Circulation. 2013; 127:720-729. DOI: 10.1161/CIRCULATIONAHA.112.114389

45. Reddy VY. Long term results of PROTECT AF: The mortality effects of left atrial appendage closure versus warfarin for stroke prophylaxis in AF. Paper presented at: Heart Rhythm Society Scientific Sessions; May 8-11, 2013; Denver, CO.

46. Reddy VY, Holmes D, Doshi SK, Neuzil P, Kar S. Safety of percutaneous left atrial appendage closure: Results from the
Watchman left atrial appendage system for embolic protection in patients with AF (PROTECT AF) clinical trial and continued access registry. Circulation. 2011;123:417-424. DOI: 10.1161/CIRCULATIONAHA.110.976449

47. Holmes DR, Kar S, Price MJ, Whisenant $B$, Sievert H, Doshi SK, Huber K, Reddy VY. The prospective randomized evaluation of the watchman left atrial appendage closure device in patients with atrial fibrillation versus long-term warfarin therapy (The PREVAIL trial). J Am Coll Cardiol. 2014; 64: 1-12. DOI: 10.1016/j.jacc.2014.04.029

48. Reddy VY, Möbius-Winkler $S$, Neuzil $P$, Schuler G, Wiebe J, Sick P, et al. Left atrial appendage closure with the WATCHMAN device in patients with a contraindication for oral anticoagulation: The ASAP study (ASA Plavix Feasibility Study With Watchman Left Atrial Appendage Closure Technology). J Am Coll Cardiol. 2013;61: 2551-2556. DOI: 10.1016/j.jacc.2013.03.035

49. Bartus K, Han FT, Bednarek J, Myc J, Kapelak B, Sadowski J, et al. Percutaneous left atrial appendage suture ligation using the lariat device in patients with atrial fibrillation: Initial clinical experience. J Am Coll Cardiol. 2013;62:108-118. DOI: 10.1016/j. jacc.2012.06.046

50. Price MJ, Gibson DN, Yakubov SJ, Schultz JC, Di Biase L, Natale A, et al. Early safety and efficacy of percutaneous left atrial appendage suture ligation: Results from the U.S. Transcatheter LAA Ligation Consortium. J Am Coll Cardiol. 2014;64: 565-572. DOI: 10.1016/j.jacc.2014.03.057

51. Giedrimas E, Lin AC, Knight BP. Left atrial thrombus after appendage closure using LARIAT. Circ Arrhythm Electrophysiol. 2013;6:e52-e53. DOI: 10.1161/CIRCEP.113.000532

52. Briceno DF, Fernando RJ, Laing ST. Left atrial appendage thrombus post LARIAT closure. Heart Rhythm. 2014;11:1600-1601. DOI: 10.1016/j.hrthm.2013.10.053

53. Camm AJ, Lip GY, De Caterina R, Savelleva I, Atar D, Hohnloser SH, et al. 2012 focused update of the ESC Guidelines for the management of atrial fibrillation: an update of the 2010 ESC Guidelines for the management of atrial fibrillation. Developed with the special contribution of the European Heart Rhythm Association. Eur Heart J. 2012;33:2719-2747. DOI: 10.1093/ eurheartj/ehs 253

54. January CT, WAnn LS, Alpert JS, Calkins $H$, Cleveland JC, Cigarroa JE, et al. 2014 AHA/ ACC/HRS Guideline for the management of patients with atrial fibrillation: A report of the American College of Cardiology/ 
American Heart Association Task Force on practice guidelines and the Heart Rhythm Society. Circulation. 2014; published online before print March 28, 2014.

55. Pister R, Lane DA, Nieuwlaat R, de Vos $C B$, Crijns HJ, Lip GY. A novel user- friendly score (HAS-BLED) to assess 1-year risk of major bleeding in patients with atrial fibrillation: The Euro Heart Survey. Chest. 2010;138:1093-1100. DOI: 10.1378/ chest.10-0134
Cite this article as: Sánchez JM, Holmes DR. Where Do We Stand Now? Structural Heart Disease 2016;2(1):114. DOI: http://dx.doi.org/10.12945/j. jshd.2015.006.14 